\title{
ELECCIONES MUNICIPALES FRANCESAS (MARZO 1983)
}

Durante el pasado mes de marzo, y en la semana comprendida del 6 al 13, se desarrollaron en Francia las elecciones municipales. Estas se presentaron como un test para la Administración socialista del presidente Mitterrand.

La reforma del sistema electoral, con su compleja combinación de escrutinio mayoritario y proporcional a dos vueltas propiciaría el incremento de votos nulos.

La batalla de las municipales tendría como elementos de referencia para establecer los resultados políticos, los escrutinios de las 538 ciudades de más de 30.000 habitantes, y muy particularmente las comunidades de París, Lyon y Marsella.

La primera vuelta se presentó como un naufragio para la mayoría socialista y comunista, y una victoria para la oposición; efectivamente, la oposición, con el 50,89 por 100 de los votos, pasaba a ser mayoritaria en el país, mientras que la mayoría parlamentaria recogía tan sólo el 39,75 por 100 de los votos. Las causas que motivaron ese resultado electoral son fácilmente deducibles; la oposición durante la campaña electoral había insistido en crear la atmósfera de que el voto municipal expresaría la sanción o aprobación de la política llevada a cabo por socialistas y comunistas desde 1981. Así, las papeletas de buena parte del electorado francés reflejaron en esta primera vuelta su desencanto.

En las anteriores municipales, en 1977, se dio el caso contrario; la izquierda capitalizó el descontento producido por la política de Giscard d'Estaing. También se quiso ver en el fracaso para los socialistas de esta primera vuelta el deseo de crear un contra-poder local frente al cuasi monopolio de socialistas y comunistas en la esfera legislativa y ejecutiva. Las pérdidas sufridas, pues, por la coalición comunista-socialista fueron considerables especialmente para el PCF, que perdería el control de importantes bastiones como Saint-Etienne (florón de las alcaldías comunistas), Besjers, Eperney y algunas de las ciudades denominadas el cinturón rojo de París.

La prensa en general, y en todo su espectro político e ideológico, pulsó y reconoció la victoria de la derecha en esta primera vuelta. Así, desde Le Figaro, Liberation, Le Quotidien de Paris, Le Monde, Le Matin e incluso L'Humanité lo demuestran.

Tampoco fueron muy propicias las municipales para los movimientos autonomistas o independientes franceses. Estos estaban presentes fundamentalmente en Córcega y el País Vasco francés.

La segunda vuelta supuso una rectificación por parte del electorado de la izquierda, que en fecha 13 de marzo y tras el voto de censura de su abstención que 
había infligido a los socialistas en la primera vuelta del día 6 de marzo consideró que había llegado el momento de modificar la tendencia electoral; así, pues, en esta segunda vuelta todos los ministros que estaban en ballottage son elegidos o reelegidos por un amplio porcentaje de sufragios, como el primer ministro Pierre Mauroz, que obtiene casi un 53 por 100 de votos en su ciudad de Lille, o el ministro del Interior, Gaston Defferre, que es reelegido, obteniendo sus listas la victoria en los tres sectores de Marsella, que están en litigio. La seria advertencil de la primera vuelta, con siete ministros derrotados y diez en ballottage, se rectifica; todos los ministros que estaban en ballottage son reelegidos; estos ministros eran, además del jefe del Gobierno y el de Interior, el de Defensa, Industria, Agricultura, Asuntos Sociales, Economía, Energía, Familia y Vejez. Frente a esta recuperación del sector socialista durante la segunda vuelta, que atenúa así su echec de la primera vuelta, queda a la oposición la inmensa satisfacción de haber contribuido al equilibrio de la vida política francesa con sus triunfos en París y Lyon, siendo el RPR, con Jacques Chirac, el gran vencedor, logrando la proeza de ganar en los veinte distritos de París.

Los neogaullistas ganan, ellos solos, 18 grandes ciudades, mientras que sus amigos de la UDF sólo triunfan en seis. Durante la primera vuelta se observó que la mayoría presidencial resistía mejor en las ciudades de talla media que en las grandes. Así, la oposición controlaría en la segunda vuelta dos de cada tres ciudades con una población superior a los 100.000 habitantes.

Al final de las dos vueltas, las urnas arrojarían estos resultados esquemáticos: 31 ciudades, con una población superior a 30.000 habitantes, han pasado de la izquierda a la derecha; las dos grandes metrópolis, París y Lyon, han sido copadas por la oposición, que es mayoritaria en todos los distritos. En síntesis, más de la mitad del electorado, el 53 por 100 , votó por los partidos conservadores, contra sólo un 47 por 100 de socialistas, comunistas y otras formaciones de izquierda.

A continuación ofrecemos unos cuadros de las elecciones en las dos vueltas, tanto de los resultados en votos de la primera y segunda vuelta como de los resultados en escaños en primera y segunda vuelta.

Estos datos han sido conseguidos, a través de la Embajada de Francia, en Regards sur L'Actualité, núm. 90, abril 1983, y Le Monde, 8 y 15 marzo 1983. Siendo éstos los datos definitivos de la fuente del Ministerio del Interior. 


\section{CUAdro NúM. 1}

\section{RESULTADOS EN VOTOS DE LA PRIMERA VUELTA}

(6 MARZO 1983)

\begin{tabular}{|c|c|c|c|c|c|c|c|c|c|c|}
\hline \multirow[t]{2}{*}{$\cdots$} & \multicolumn{2}{|c|}{$\begin{array}{l}\text { Comunidades de } \\
\text { menos de } 3.500 \mathrm{~h} .\end{array}$} & \multicolumn{2}{|c|}{$\begin{array}{l}\text { Comunidades de } \\
3.500 \text { a } 9.000 \mathrm{~h} \text {. }\end{array}$} & \multicolumn{2}{|c|}{$\begin{array}{l}\text { Comunidades de } \\
9.000 \text { a } 30.000 \mathrm{~h} .\end{array}$} & \multicolumn{2}{|c|}{$\begin{array}{l}\text { Comunidades de más } \\
\text { de } 30.000 \mathrm{~h} \text {. }\end{array}$} & \multicolumn{2}{|c|}{$\begin{array}{l}\text { Conjunto de } \\
\text { comunidades }\end{array}$} \\
\hline & Votos & $\%$ & Votos & $\%$ & Votos & $\%$ & Votos & $\%$ & Votos & $\%$ \\
\hline Inscritos $\ldots$ & 14.421 .378 & - & 4.873 .886 & - & 6.382 .923 & '- & 10.555 .394 & - & 36.233 .581 & - \\
\hline Votantes $\ldots \ldots \ldots \ldots \ldots \ldots \ldots$ & 12.328 .520 & 85,48 & 3.918 .052 & 80,38 & 4.766 .657 & 74,67 & 7.381 .029 & 69,92 & 28.394 .258 & 78,36 \\
\hline Efectivos $\ldots \ldots \ldots \ldots \ldots \ldots$ & 11.933 .572 & $82,7.4$ & 3.754 .142 & 77,02 & 4.623 .580 & 72,43 & 7.208 .850 & 68,29 & 27.520 .144 & 75,95 \\
\hline Abstenciones $\quad . . . . . . . . . . .$. & 2.092 .858 & 14,51 & 955.834 & 19,61 & 1.616 .266 & 25,32 & 3.174 .365 & 30,07 & 7.838 .323 & 21,63 \\
\hline Liste Extr: gauche ... & 4.995 & 0,05 & 4.702 & 0,12 & 17.544 & 0,37 & 110.815 & 1,53 & 138.056 & 0,54 \\
\hline Liste Parti Comm. ........ & 153.386 & 1,56 & 144.837 & 3,85 & 177.841 & 3,84 & 123.447 & 1,71 & 599.511 & 2,36 \\
\hline Liste Majorité .............. & 1.644 .220 & 16,77 & 1.194 .873 & 31,82 & $1.659,520$ & 35,39 & 2.782 .520 & 37,48 & 7.201 .133 & 28,36 \\
\hline Liste Parti Soc. ............ & 490.847 & 5,00 & 259.303 & 6,90 & 256.716 & 5,55 & 199.296 & 2,76 & 1.206 .162 & 4,75 \\
\hline Liste Div. gauche ......... & 744.568 & 7,59 & 79.529 & 2,11 & 74.951 & 1,62 & 49.394 & 0,68 & 948.442 & 3,73 \\
\hline Liste Gauche cent. ........ & 1.937 .286 & 19,76 & 205.220 & 5,46 & .44 .304 & 0,95 & 40.109 & 0,55 & 2.226 .919 & 8,77 \\
\hline Liste Ecologistes .......... & 5.406 & 0,05 & 5.629 & 0,14 & 21.106 & 0,45 & 115.743 & 1,60 & 147.884 & 0,58 \\
\hline Liste Opposition .......... & 4.822 .949 & 49,19 & 1.859 .786 & 49,53 & 2.371 .120 & $51 ; 28$ & 3.840 .457 & 53,27 & 12.894 .312 & $.50,78$ \\
\hline Liste Extr. droite ......... & 160 & - & 263 & - & 478 & 0,01 & 27.069 & 0,37 & 27.970 & 0,11 \\
\hline
\end{tabular}

Indice de siglas:

- La denominación Liste Mayorité concentra las listas de unión de la mayoría (PS, PC, MRG, etc.).

- Liste Opposition: reagrupa las listas VDF, RPR y las listas de Unión de la Oposición.

- Liste Extr. gauche: L. extrema izquierda.

Liste Parti Soci: L. Partido Socialista.

- Liste Div gauche: L Div irquierda.

- Liste Gauche cent . I izquierda cent.

- Liste Ecologistes: L. ecologistas.

- Liste Extr. droite: L. extrema derecha 
Cuadro núm. 2

RESULTADOS EN VOTOS DE LA SEGUNDA VUELTA (13 MARZO 1983)

\begin{tabular}{|c|c|c|c|c|c|c|c|c|c|c|}
\hline & \multicolumn{2}{|c|}{$\begin{array}{l}\text { Comunidades de } \\
\text { menos de } 3.500 \mathrm{~h} .\end{array}$} & \multicolumn{2}{|c|}{$\begin{array}{l}\text { Comunidades de } \\
3.500 \text { a } 9.000 \mathrm{~h} .\end{array}$} & \multicolumn{2}{|c|}{$\begin{array}{l}\text { Comunidades de } \\
9.000 \text { a } 30.000 \mathrm{~h} .\end{array}$} & \multicolumn{2}{|c|}{$\begin{array}{l}\text { Comunidades de más } \\
\text { de } 30.000 \mathrm{~h} .\end{array}$} & \multicolumn{2}{|c|}{$\begin{array}{l}\text { Conjunto de } \\
\text { comunidades }\end{array}$} \\
\hline & Votos & $\%$ & Votos & $\%$ & Votos & $\%$ & Votos & $\%$ & Votos & $\%$ \\
\hline $\begin{array}{l}\text { Inscritos } \quad \ldots \ldots \ldots \ldots \ldots \ldots \ldots \\
\text { Votantes } \quad \ldots \ldots \ldots \ldots \ldots \ldots \ldots \ldots \\
\text { Efectivos } \quad \ldots \ldots \ldots \ldots \ldots \ldots \ldots \ldots \\
\text { Abstenciones } \quad \ldots \ldots \ldots \ldots \ldots \ldots\end{array}$ & $\begin{array}{l}7.440 .415 \\
6.140 .609 \\
5.965 .421 \\
1.299 .806\end{array}$ & $\begin{array}{l}-\overline{82,53} \\
80,17 \\
17,46\end{array}$ & $\begin{array}{r}1.315 .756 \\
1.075 .523 \\
1.049 .803 \\
240.233\end{array}$ & $\begin{array}{l}\overline{81,74} \\
79,78 \\
18,25\end{array}$ & $\begin{array}{r}1.721 .303 \\
1.328 .286 \\
1.294 .688 \\
392.918\end{array}$ & $\begin{array}{l}-\overline{77,17} \\
75,21 \\
22,82\end{array}$ & $\begin{array}{r}3.350 .387 \\
2.474 .767 \\
2.418 .570 \\
875.620\end{array}$ & $\begin{array}{l}\overrightarrow{73.86} \\
72,18 \\
26,13\end{array}$ & $\begin{array}{r}13.827 .862 \\
11.019 .285 \\
10.728,482 \\
2.808 .577\end{array}$ & $\begin{array}{l}79.68 \\
77,58 \\
20,31\end{array}$ \\
\hline 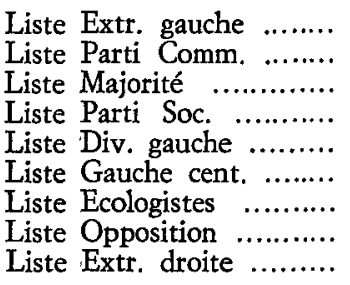 & $\begin{array}{r}3.336 \\
74.931 \\
792.340 \\
243.290 \\
513.524 \\
870.575 \\
4.717 \\
2.449 .239 \\
831\end{array}$ & $\begin{array}{r}0,06 \\
1,51 \\
15,99 \\
4,91 \\
10,36 \\
17,57 \\
0,09 \\
49,45 \\
0,01\end{array}$ & $\begin{array}{r}\overline{24.748} \\
344.225 \\
48.125 \\
31.992 \\
90.458 \\
403 \\
509.667 \\
185\end{array}$ & $\begin{array}{r}\overline{2,35} \\
32,78 \\
4,58 \\
3,04 \\
8,61 \\
0,03 \\
48,54 \\
0,01\end{array}$ & $\begin{array}{r}\overline{18.688} \\
543.263 \\
32.007 \\
22.163 \\
24.794 \\
2.779 \\
650.995 \\
-\end{array}$ & $\begin{array}{r}\overline{1,44} \\
41,96 \\
2,47 \\
1,71 \\
1,91 \\
0,21 \\
50,28 \\
-\end{array}$ & $\begin{array}{r}- \\
6.964 \\
1.101 .453 \\
56.885 \\
7.472 \\
13.234 \\
\overline{-} \\
1.227 .053 \\
5.509\end{array}$ & $\begin{array}{r}\overline{9,28} \\
45,44 \\
2,35 \\
0,30 \\
0,34 \\
-1 \\
50,73 \\
0,22\end{array}$ & $\begin{array}{r}3.336 \\
125.331 \\
2.781 .280 \\
380.307 \\
575,151 \\
999.061 \\
7.899 \\
4.836 .954 \\
6.525\end{array}$ & $\begin{array}{r}0,03 \\
1,28 \\
28,62 \\
3,91 \\
5,91 \\
10,28 \\
0,08 \\
49,78 \\
0,06\end{array}$ \\
\hline
\end{tabular}

Indice de siglas:

- La denominación Liste Mayorité concentra las listas de unión de la mayoría (PS, PC, MRG, etc.).

- Liste Opposition: reagrupa las listas VDF, RPR y las listas de Unión de la Oposición.

二 Liste Extr. gauche: L. extrema izquierda.

二 Liste Parti Comm.: L. Partido Comunista.

- Liste Div. gauche: L. Div. izquierda.

- Liste Gauche cent.: L. izquierda cent.

- Liste Ecologistes: L. ecologistas. 
CuAdro NúM. 3

RESULTADOS EN ESCANTOS TRAS LAS DOS VUELTAS

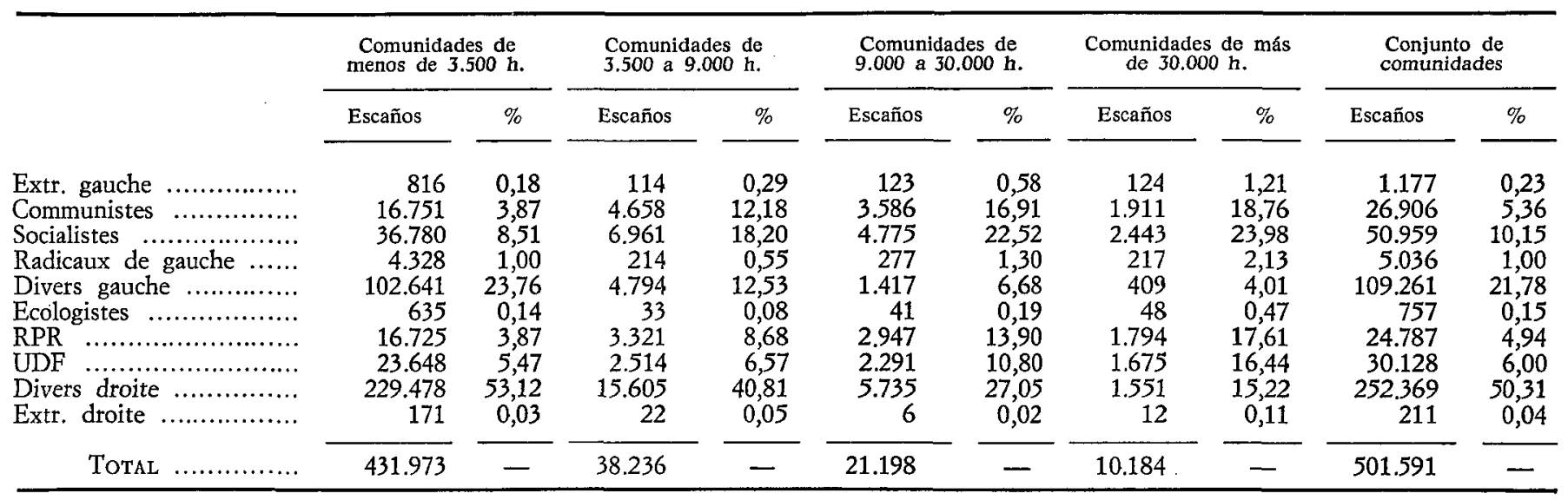

